talenta

\title{
EVALUATION OF RENAL FUNCTION BEFORE AND AFTER CHEMOTHERAPY IN NASOPHARYNGEAL CARCINOMA IN LOMBOK
}

\author{
Hamsu Kadriyan $^{1 *}$, Muhammad Alfian Sulaksanal, Nurhidayati ${ }^{2}$, Baiq Endang Suprihartini ${ }^{3}$ \\ ${ }^{I}$ Department of ENT HNS, Faculty of Medicine, Mataram University, Mataram, Nusa Tenggara Barat, Indonesia \\ ${ }^{2}$ Department of Pharmacology, Faculty of Medicine, Mataram University, Mataram, Nusa Tenggara Barat, Indonesia \\ ${ }^{3}$ Pharmacy Study Program, Nahdlatul Wathan University, Mataram, Nusa Tenggara Barat, Indonesia
}

\section{Abstract}

Introduction: Combination of chemotherapy and radiation are the treatment of choice in advance stage of nasopharyngeal carcinoma. Cisplatin-based chemotherapy is a regiment of choice in those cases. Several studies show that cisplatin-based chemotherapy affect renal function.

Objective: To evaluate and compare the renal function before and after chemotherapy through comparing the blood urea nitrogen and creatinine serum level in patients with nasopharyngeal cancer who receive cisplatin and paclitaxel chemotherapy.

Method: Using Medical records data for study design. Design of this study is before and after using medica records data in West Nusa Tenggara General Hospital in Lombok.

Result: There were 33 patients who fulfill the inclusion and exclusion criteria in this study. Most of the patients are male with male and female ratio $3: 1$. The youngest patient age is eight years old, on the other hand, the oldest is 70 years old with the average age 46.6 years old. According to histopathology finding, on this study researcher didn't found WHO type I and most the patients were WHO type III ( $89.9 \%$ ). The mean blood urea nitrogen concentration before chemotherapy is 25.00 and after the treatment 33.33 with the p-value 0.01 with the paired t-test. On the other hand, creatinine serum level before and after chemotherapy consecutively 0.99 and 1.10. P value 0.15 , or there is no significant difference.

Conclusion: Blood urea nitrogen and creatinine serum are increase after cisplatin-based chemotherapy. However, only BUN has a significant difference.
\end{abstract}

\section{Article Info}

Keywords:

Cisplatin-based chemotherapy, renal function, nasopharyngeal carcinoma

\section{*Corresponding author:}

Address: Jalan Jenderal Sudirman No 9 C

Mataram, Nusa Tenggara Barat, Indonesia

e-mail:

hamsu@unram.ac.id/hamsukadriyan@yahoo.co.id

\section{INTRODUCTION}

Lombok is one of the beautiful islands in Indonesia. It lies in the middle part of Indonesia and surrounded by a beautiful beach. Because of its location, most of their citizen consume the fish and its products such as salted fish and fermented shrimpfish. Salted fish and other corned food are recognized as one of the risk factors for the development of nasopharyngeal carcinoma [1]. Salted fish consumption recognized as a $3^{\text {rd }}$ most risk factors on nasopharyngeal carcinoma [2].

Similar to other regions in Indonesia, the cases of nasopharyngeal carcinoma are relatively high. The research in Lombok in 2015 found that 48 patients with undifferentiated squamous cell carcinoma [3]. In advanced, the Incidence of nasopharyngeal carcinoma in Indonesia is predicted about 5.6/100.000 people or there will be 15.000 cases annually [4]. According to global cancer statistic (GLOBOCAN) 2018, there are 129.079 new cases worldwide or $0.7 \%$ of all cancer cases with 72.987 death due to nasopharyngeal carcinoma annually [5].

The more, unfortunately, the cases usually found in the advanced stage. This lead to the need for chemotherapy on its treatment. According to NCCN, advance nasopharyngeal carcinoma should be treated with a combination of radiotherapy and chemotherapy. Chemotherapy could be given in the scheme of adjuvant, neoadjuvant, concurrent or concomitantly [6]

Chemotherapy of choice in nasopharyngeal carcinoma is using the platinum-based. On the other hand, due to this medicine containing heavy metal, this substance may affect several organs, including renal function. Estimated $20 \%$ of patient who receives cisplatin have a renal dysfunction and $33 \%$ of them experience an acute kidney injury [7]. Arunkumar et al. (2012) found there was a significant difference of serum creatinine between before and post-chemotherapy with cisplatin in a patient with squamous cell carcinoma head and neck. The mean concentration of creatinine before and post-chemotherapy consecutively $(0.73 \pm 0.08$ and $1.07 \pm 1.19$ with $\mathrm{P}<0.05)$. On the other hand, the level of blood urea nitrogen (BUN) is decreased significantly [8]. Tezcan et al. (2013), found both BUN and creatinine are increased significantly after three cycles of cisplatin administration [9].

In West Nusa Tenggara hospital, most of the patient with nasopharyngeal carcinoma was treated with a combination of cisplatin and paclitaxel, although the NCCN recommended a combination of cisplatin 5-FU as first-line treatment. This is due to a shorter time of hospitalization and the effectiveness is comparable with a combination of cisplatin-5FU [6]. According to those, our team is interesting to investigate the BUN and creatinine serum level before and after chemotherapy with cisplatin and paclitaxel.

The aim of this study are to evaluate and compare the renal function before and after chemotherapy through comparing the blood urea nitrogen and creatinine serum level in patients with nasopharyngeal carcinoma who receive cisplatin and paclitaxel chemotherapy. Besides, this study could be used as a references for doing a renal function monitoring for nasopharyngeal carcinoma patients treated by chemotherapy.

\section{MATERIAL AND METHODS}

This study is conducted before and after methods, by using retrospective data in West Nusa Tenggara General Hospital. The data was compiled through the medical record to find out all of the patients with nasopharyngeal carcinoma stage III and IV since 2016-2018 who receive the platinum-based chemotherapy (cisplatin and paclitaxel). Data which will be collected including the age, sex, stage of cancer, histopathology, the serum level of blood urea nitrogen and creatinine. The data will arrange and analysis with paired t-test to knows a different concentration or level of blood urea nitrogen and creatinine before and after chemotherapy. Patients with incomplete data will be excluded. 


\section{RESULT}

In this study, there are 33 patients with nasopharyngeal carcinoma who fulfilled the inclusion and exclusion criteria. Most of the patients are male with male and female ratio 3:1. The youngest patient age is 8 years old, on the other hand, the oldest is 70 years old with the average age 46.6 years old. According to histopathology finding, on this study researcher didn't found WHO type I and most of the patients were WHO type III $(89.9 \%)$. This data is shown in table 1 .

Table 1. Characteristic of patients

\begin{tabular}{lcc}
\hline \multicolumn{1}{c}{ Characteristics } & Frequency & Percentage \\
\hline Ages & 8 & 2 \\
Youngest & 70 & 2 \\
Oldest & 46.6 & \\
Mean & 21 & 63.6 \\
Sex & 12 & 36.4 \\
Male & 20 & 60.6 \\
Female & 13 & 29.4 \\
Stage & & \\
III & 0 & 0 \\
IV & 3 & 9.1 \\
Histopathology & 30 & 89.9 \\
WHO type I & & \\
WHOO Type II & & \\
WHO type III &
\end{tabular}

According to the laboratory result, the mean blood urea nitrogen concentration before chemotherapy is 25.00 and after the treatment 33.33 with the p-value 0.01 , the paired t-test result as shown in table 2. On the other hand, creatinine serum level before and after chemotherapy consecutively 0.99 and 1.10. $\mathrm{P}$ value $>0.05$, or there is no significance difference.

Table 2. The paired t-test for the concentration of Urea and creatinine

\begin{tabular}{lcccc}
\hline \multicolumn{1}{c}{ Variable } & Mean Before & Mean After & $\begin{array}{c}\text { Standard } \\
\text { deviation }\end{array}$ & P value \\
\hline Blood Urea Nitrogen (BUN) & 25.00 & 33.33 & 14.66 & 0.01 \\
Creatinine & 0.99 & 1.10 & 0.41 & 0.15 \\
\hline
\end{tabular}

\section{DISCUSSION}

The general characteristic of the patient in this study is similar to another previous study. In our study the male to male ratio is $3: 1$, the mean age is 46.6 years old and $89.9 \%$ is WHO type III. Adham et al (2012) found the most age between 30-50 years old with the most histopathologic finding was WHO type III (85\%) [4]. Peng et al (2016) found a male to male ratio $4: 1$ and $99.8 \%$ with WHO type II and III [10].

Several studies showed that platinum-based chemotherapy has an effect on renal function [7], [8], [9], [10]. Cisplatin is excreted through the kidney, furthermore, its logic that cisplatin may affect the kidney function. Review by Miller et al. (2010) who describe the mechanisms of cisplatin nephrotoxicity states that injury of the kidney may happen by the accumulation of cisplatin on kidney cell, biotransformation of cisplatin in kidney, mediated the cytotoxic effect on DNA and apoptotic pathways of cisplatin cytotoxicity [11]. According Ozkok et al (2014) on their review, states that the general pathophysiology of cisplatin on acute kidney injury involves 4 major mechanisms: (1) proximal tubular injury, (2) oxidative stress, (3) inflammation, and (4) vascular injury in the kidney [12].

In this study, there is an increasing level of blood urea nitrogen and creatinine before and after chemotherapy. However, only BUN has a significant difference before and after chemotherapy. Although creatinine serum level increase after chemotherapy, but its difference is not significant. This result indicated the occurrence of kidney injury.

Latcha et al. (2016) found an increase of mean serum creatinine level from 0.99 to $1.18 \mathrm{mg} / \mathrm{dl}$ after first cisplatin administration and remain in the level of $1.14 \mathrm{mg} / \mathrm{dl}$ a year post-chemotherapy [13]. Arunkumar et al. (2010) found a significant serum creatinine level before and after five cycles of cisplatin administration (from 0.78 to $1.13 \mathrm{gr} / \mathrm{dl}$ ), but BUN is not significant although there is an increase (from 12.28 to $13.35 \mathrm{gr} / \mathrm{dl}$ ) [8]. Noviyani et al. (2017) on prospective studies found there is no significant difference between BUN and creatinine serum in patients with 6 cycles paclitaxel and cisplatin [14].

Another marker to knows the effect of chemotherapy to renal function is glomerulal filtration rate (GFR). Loh et al (2017) on their research on urothelial cancer found that Median GFR change was $1.6 \%$ for patients with pretreatment GFR $<60 \mathrm{~mL} / \mathrm{min}$ compared to $10.9 \%$ for patients with pre- treatment GFR $>60$ $\mathrm{mL} / \mathrm{min}$ (P 1/4 .17). They concluded that urothelial cancer patients with GFR < $60 \mathrm{~mL} / \mathrm{min}$ do not experience a greater decline in renal function after cisplatin compared to patients with GFR $>60 \mathrm{~mL} / \mathrm{min}$ [15].

According to those references, not all studies agree with the renal effect of cisplatin-based chemotherapy. Miller (2010) explained several risk factors make the increase of cisplatin nephrotoxicity, including dose and frequency of administration, cumulative dose, older age, female sex, smoking, hypoalbuminemia, and pre-existing renal insufficiency. On the other hand, factors such as diabetes and OCT2 polymorphisms have decreased the risk of renal dysfunction [11]. Hayati et al (2016) on his mini review found the most important risk factors for cisplatin induced nephrotoxicity including higher doses of cisplatin, previous cisplatin chemotherapy, underlying kidney damage and concurrent treatment with other potential nephrotoxin agents, such as aminoglycosides, nonsteroidal anti-inflammatory agents, or iodinated contrast media. [16]

In this study, maybe because of mean age is under 50 years and predominantly male, lead to a decrease of nephrotoxicity. The low BUN and creatinine in this study are healthy, this is also lead to a lower effect of cisplatin-based chemotherapy. However, more detailed research should be done to make sure the exact effect of cisplatin-based to the renal function in nasopharyngeal carcinoma patients. Future research with larger samples could give more accurate and valid result.

\section{CONCLUSION}

Blood urea nitrogen and creatinine serum are increase after cisplatinpaclitaxel chemotherapy. However, only BUN has a significant difference. This result indicated the occurance of kidney injury.

\section{REFERENCE}

[1] Adham M. Nasopharyngeal carcinoma understanding the anatomy, Ebv marker, and clinical presentation. In: Farhat, editor. Scientific Paper Compilation 1st National Conference of Nasopharyngeal Carcinoma; "Prevention is Better than Cure"USU Press. 2018.

[2] Hardianti RA, Dewi YA. Risk factor of nasopharyngeal cancer in DR. Hasan Sadikin General Hospital Bandung. In: Farhat, editor. Scientific Paper Compilation 1st National Conference of Nasopharyngeal Carcinoma; "Prevention is Better than Cure"USU Press. 2018

[3] Kadriyan H. Epidemiology of nasopharyngeal cancer and the opportunity to explore several characteristic. Universitas Mataram. 2018.

[4] Adham M KA, Muhatdi AI, Roezin A, et al. Nasopharyngeal carcinoma in Indonesia: epidemiology, incidence, sign, and symptoms at presentation. Chines Journal of Cancer. 2012;31(4):185-96.

[5] Bray F, Ferlay J, Soerjomataram I, Siegel RL, Torre LA, Jemal A. Global Cancer Statistics 2018: GLOBOCAN Estimates of incidence and mortality worldwide for 36 cancers in 185 countries. CA Cancer Journal for Clinicians. 2018;68: 394-424.

[6] NCCN Guidelines: Head and neck cancer. In: DG P, editor. NCCN.org 2018.

[7] Gi-Su O H-JK, AiHua S, Su BL, Dipendra K. Cisplatin-induced kidney dysfunction and perspectives on improving treatment strategies. Electrolyte Blood Press. 2014;12:56-65.

[8] Arunkumar PA VG, Radheshyam N, Mukund H, Bellyappa MS. Science behind cisplatin-induced nephrotoxicity in humans: A clinical study. Asian Pasific Journal of Tropical Biomedicine. 2012;2(8):640-4.

[9] Tezcan S IF, Sancar M, Yumuk PF, Turhal S. Nephrotoxicity evaluation in outpatient treated with cisplatin-based chemotherapy using a short hydartion method. Pharmacology \& Pharmacy. 2013;4:296-302.

[10] Peng H CL, Li WF, Guo R, Mao YP, Zhang Y, et al. The cumulative cisplatin dose affects the longterm survival outcomes of patients with nasopharyngeal carcinoma recieving concurent chemoradiotherapy. Scientific report. 2016;6(24332):1-8.

[11] Miller RP TR, Ramesh G, Reeves WB. Mechanisms of cisplatin nephrotoxicity. Toxins. 2010;2:2490-518.

[12] Ozkok A, Eldestein CL. Pathophysiology of Cisplatin-induced acute kidney injury. BioMed Research International.2014:1-17.

[13] Latcha S JE, Patil S, Glezerman IG, et al. Long-term renal outcomes after cisplatin treatment. Clinical journal of American Society of Nephrology. 2016;11:1173-9.

[14] Noviyani R IP, Thabrany H, Andrijono, Budiana NG. Difference in the value of bloodurea nitrogen and creatinine serum in cervical cancer squamous cell stadium IIB-IIIB before and after chemotherapy paclitaxel cisplatin for six cycles in Sanglah general hospital Denpasar, Bali. Asian journal of pharmaceutical and clinical research. 2017;10(2):381-4.

[15] Loh JM, Tran AL, Ji L,Groshen S, Daneshmand S, Schuckman A, Quinn DI, Dorff TB. Baseline glomerular filtration rate and cisplatin- induced renal toxicity in urothelial cancer patients. Clinical Genitourinary Cancer. 2017;16(1): 90-8.

[16] Hayati F, Hossainzadeh M, Shayanpour S, Abedi-Gheshlaghi Z, Mousavi SSB Prevention of cisplatin nephrotoxicity. Journal of Nephropharmacology. 2016;5(1): 57-60. 